\title{
Robert Elliott Smith: Rage Inside the Machine-the prejudice of algorithms, and how to stop the internet making bigots of us all
}

\section{Bloomsbury business, 2019, 344 pp., ISBN 9781472963888}

\author{
Walid Magdy ${ }^{1,2}$
}

Received: 24 September 2021 / Accepted: 25 September 2021 / Published online: 25 October 2021 (C) The Author(s), under exclusive licence to Springer Science+Business Media, LLC, part of Springer Nature 2021

Rage Inside the Machine is a unique book that cannot be compared to other books about technology. Knowing it was written by Rob Smith, a well-known professor in the field of Artificial Intelligence (AI) at UCL, I expected to read a technical book with potentially some focus on the applications based on his wide range of experience. However, it was totally different.

It is hard to describe the genre of this book, since it is a combination of many disciplines that are connected in a clever way to discuss the evolution of algorithms, machines, and AI. It includes topics related to: history, technology, mathematics, biology, politics, art, linguistics, economics, some drama, and many philosophical discussions. All these are well organized in a sequence of chapters showing the origin of the algorithms and machines in human history, their applications in many different areas, and their relation to economical, evolution, and linguistic theories. It also includes some stories from the author's own experience in a nice well integrated drama.

I learned a lot from reading this book. In fact, it took longer to read than I expected, since it discusses some historical stories and biographic information about the characters in those stories, which motivated me to find out more about them. Thus, while reading, you can find yourself searching the web for more information about those historic stories and their characters in order to realize how they have affected today's machines. This combination is a special achievement of this book that no other book on the subject has covered.

Rage Inside the Machine shows not just how machines have developed over centuries, but also across many disciplines. Furthermore, it provides nice information

Walid Magdy

wmagdy@inf.ed.ac.uk

1 The University of Edinburgh, Edinburgh, UK

2 The Allan Turing Institute, London, UK 
about the creators of these scientific/engineering developments. You will learn about their characters, personalities, social status, and the life challenges they faced. In the book you will read about the development of mathematics over years since algorithms were introduced as Latinisation of Al-Khwarizmi the mathematician, passing by the Gaussian bell curve, the evolution theory of Darwin and its developments, the economic theory of Adam Smith, the linguistic theory of Noam Chomsky, and many others, showing the evolution of machines over centuries.

Also, what is amazing in this book is the philosophical discussions about AI and its meaning. I totally agree with Smith's argument about how terms have different meanings when speaking about machines vs humans, such as the words "intelligence" and "learning". How humans have tried to simplify the term intelligence into measurable terms such as IQ tests, and this is the case when simplifying current tasks performed by AI though representations of features (or atoms as Smith calls them) and how this can be problematic. This philosophical discussion highlights the danger of using AI as it is now. The dangers of us relying on it, and how it can be biased. I also agree with Smith's emphasis that we are far from replicating human intelligence, since reasoning and intelligence of the machine is totally different from how we think and behave.

I believe this book is an excellent read for anyone who is interested in AI or engineering in general. It gives a different view and excellent history of how we reached the situation we are in now. It helps in shaping our thoughts on how we can proceed while being aware of the challenges and dangers we may face. Smith shows his wide range of knowledge in history across many fields and has managed to bring this all into one book which has information that was previously hard to acquire from one place.

I highly recommend Rage Inside the Machine. It is an excellent read, even for a general audience who has no background in computer science or engineering. $80 \%$ of the content are easy (and exciting) to follow for non-experts. 20\% of the book has some technical details that might require some knowledge of mathematics or AI, however these parts can be skipped without affecting the general flow of the book. Finally, there are a few paragraphs in the final chapter that I believe will be quoted in future AI work, since they summarize the current situation of AI and how we should move forward.

Publisher's Note Springer Nature remains neutral with regard to jurisdictional claims in published maps and institutional affiliations. 